\title{
Simvastatin profoundly impairs energy metabolism in primary human muscle cells
}

\author{
Selina Mäkinen ${ }^{1,2}$, Neeta Datta ${ }^{1,2}$, Yen H Nguyen ${ }^{1,2}$, Petro Kyrylenko ${ }^{1,2}$, Markku Laakso ${ }^{3}$ and Heikki A Koistinen ${ }^{1,2}$ \\ ${ }^{1}$ Minerva Foundation Institute for Medical Research, Helsinki, Finland \\ 2Department of Medicine, University of Helsinki, Helsinki University Central Hospital, Helsinki, Finland \\ ${ }^{3}$ Institute of Clinical Medicine, Internal Medicine, University of Eastern Finland, Kuopio, Finland
}

Correspondence should be addressed to H A Koistinen: heikki.koistinen@helsinki.fi

\begin{abstract}
Objectives: Simvastatin use is associated with muscular side effects, and increased risk for type 2 diabetes (T2D). In clinical use, simvastatin is administered in inactive lipophilic lactone-form, which is then converted to active acid-form in the body. Here, we have investigated if lactone- and acid-form simvastatin differentially affect glucose metabolism and mitochondrial respiration in primary human skeletal muscle cells. Methods: Muscle cells were exposed separately to lactone- and acid-form simvastatin for $48 \mathrm{~h}$. After pre-exposure, glucose uptake and glycogen synthesis were measured using radioactive tracers; insulin signalling was detected with Western blotting; and glycolysis, mitochondrial oxygen consumption and ATP production were measured with Seahorse XFe96 analyzer.

Results: Lactone-form simvastatin increased glucose uptake and glycogen synthesis, whereas acid-form simvastatin did not affect glucose uptake and decreased glycogen synthesis. Phosphorylation of insulin signalling targets Akt substrate $160 \mathrm{kDa}$ (AS160) and glycogen synthase kinase $3 \beta$ (GSK3 $\beta$ ) was upregulated with lactone-, but not with acid-form simvastatin. Exposure to both forms of simvastatin led to a decrease in glycolysis and glycolytic capacity, as well as to a decrease in mitochondrial respiration and ATP production.

Conclusions: These data suggest that lactone- and acid-forms of simvastatin exhibit differential effects on non-oxidative glucose metabolism as lactone-form increases and acid-form impairs glucose storage into glycogen, suggesting impaired insulin sensitivity in response to acid-form simvastatin. Both forms profoundly impair oxidative glucose metabolism and energy production in human skeletal muscle cells. These effects may contribute to muscular side effects and risk for T2D observed with simvastatin use.
\end{abstract}

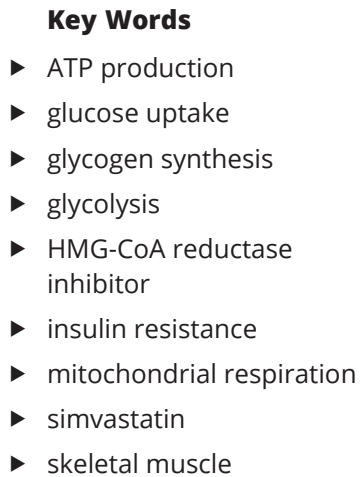

Endocrine Connections (2020) 9, 1103-1113

\section{Introduction}

HMG-CoA reductase inhibitors, statins, lower cholesterol levels by inhibiting mevalonate formation, the ratelimiting step in the cholesterol biosynthesis (1). These drugs are widely used and effective in primary $(2,3)$ and secondary (4) prevention of atherosclerotic events. However, data from several clinical studies have demonstrated that statin treatment increases the risk of type 2 diabetes (5). Statin use has been implicated with decreases in insulin secretion and whole-body insulin sensitivity (6). A large observational study has revealed that statin use is associated with higher fasting glucose concentrations (7). Statin use has also been accompanied with impairments in glycemic control and insulin secretion in patients with type 2 diabetes (8). Regarding individual statins, simvastatin or rosuvastatin use was associated with the highest risk for type 2 diabetes, (c) 2020 The authors Published by Bioscientifica Ltd
This work is licensed under a Creative Commons Attribution-NonCommercial-NoDerivatives 4.0 Internationab sicense.ifica . com at $04 / 26 / 2023 \quad 02: 43: 26 \mathrm{AM}$ 
whereas pravastatin use was associated with low risk of new-onset diabetes (9).

Statins may induce muscular side effects, ranging from mild myalgia to severe rhabdomyolysis, which may contribute to impaired glucose homeostasis (10). One proposed mechanism for muscle symptoms during statin use is the lipophilic nature of certain statins, which enables these to diffuse non-selectively into non-hepatic tissues such as skeletal muscle (11). This idea is supported by the PRIMO-study, which showed hydrophilic statins, such as pravastatin, causing less myalgia, whereas highly lipophilic simvastatin was most likely involved in muscular adverse effects (12).

The mechanisms whereby statins affect insulin sensitivity in human muscle are unclear. Simvastatininduced insulin resistance has been proposed to result from decreased lipid synthetic capacity in skeletal muscle. This may lead to intracellular accumulation of toxic fatty acid metabolites, which impairs insulin sensitivity (13). This observation is supported by the finding of larger lipid droplets in muscle cells of patients treated with statins (14). An in vitro and in vivo study using rodent models revealed a link between statin-induced myotoxicity and impairments in mTOR/Akt signalling pathway, which led to negative consequences on important cellular processes, such as skeletal muscle protein synthesis and breakdown, as well as apoptosis (15). Inhibition of Akt phosphorylation was also responsible for simvastatininduced mitochondrial dysfunction in mouse $\mathrm{C} 2 \mathrm{C} 12$ muscle cells (16). Potential mechanisms for simvastatininduced myotoxicity also include impaired mitochondrial function, increment in skeletal muscle catabolism due to increased expression of atrogin-1, reduction in skeletal muscle protein synthesis and inhibition of small GTPases due to impaired prenylation and/or impaired creatine synthesis (17).

Simvastatin is administered in inactive lipophilic lactone-form, which is then converted to active acidform in the body (10). Approximately equal amounts of lactone- and acid-forms are present in human plasma $(18,19)$. Lactone-form statins have been observed to be more prone to cause myotoxic effects (19), and thus may contribute to impairments in glucose metabolism. Glucose uptake was inhibited with lactone-form simvastatin in rat L6 myotubes via inhibition of IR/IRS-1/Akt signalling cascade (20). Moreover, a study with mouse C2C12 muscle cells demonstrated that translocation of GLUT4, an effect mediated by PI3K/Akt signalling, was inhibited and glucose uptake decreased in $\mathrm{C} 2 \mathrm{C} 12$ cells treated with lactone-form simvastatin (21). Lactone-form statins have also shown to inhibit mitochondrial complex III activity in $\mathrm{C} 2 \mathrm{C} 12$ cells (22).

In this study, we examined the effects of lactone- and acid-form simvastatin on oxidative and non-oxidative glucose metabolism, mitochondrial respiration and insulin signalling in primary human skeletal muscle cells in vitro.

\section{Materials and methods}

\section{Antibodies and reagents}

The culture medias used for muscle cell proliferation and differentiation were high-glucose DMEM/F12 (Gibco cat. 31331) and low glucose DMEM/F12 (Gibco cat. 21885), respectively. Culture media used for statin pre-treatments and serum starvation was low glucose DMEM (Sigma cat. D5546). Culture media for glucose uptake assay was glucose-free DMEM (Gibco cat. 11966). Antibiotics used in proliferation and differentiation medias were Amphotericin B from Gibco and penicillin-streptomycin solution from Sigma. FBS and L-glutamine, glycogen carrier from rat liver and cytochalasin B were from Sigma. CD56-labeled magnetic beads were from Miltenyi Biotec (Gologne, DE). Simvastatin (in lactone form) was from Calbiochem/EMD Millipore. Pravastatin was from Tocris Bioscience (Bristol, UK). Fatty-acid free BSA was from Biowest (Nuaillé, France). Actrapid Insulin was from Novo Nordisk (Bagsværd, DK). 2-[1,2- $\left.{ }^{3} \mathrm{H}\right]$-deoxy-D-glucose and D- $\left[{ }^{14} \mathrm{C}\right]$-glucose were from Perkin Elmer. Seahorse XF Glycolysis Stress Test and Mito Stress Test kits, and XF Assay media were from Agilent Technologies Inc. The cOmplete EDTA-free Protease Inhibitor Cocktail tablets and PhosSTOP phosphatase inhibitor tablets were from Roche. BCA Protein Assay kit for protein concentration measurement and ECL2 Western blotting substrate for detection of ECL were from Pierce/Thermo Scientific. PVDF membrane was from BioRad. All antibodies: pAkt-Ser ${ }^{473}$ (cat. \#9271), pAkt-Thr ${ }^{308}$ (cat. \#9275), total Akt (cat. \#9272), pAS160-Thr ${ }^{642}$ (cat. \#4288), total AS160 (cat. \#2447), pGSK3 $\beta$-Ser ${ }^{9}$ (cat. \#9336), total GSK3 $\beta$ (cat.\#9315) and total AMPK (cat. \#2532) were from Cell Signalling Technology, except pAMPK-Thr ${ }^{172}$ (cat. 07-626) was from Upstate (Lake Placid, NY, USA). Anti-rabbit HRP-conjugated secondary antibody was from Jackson ImmunoResearch Laboratories Inc.

\section{Subjects and preparation of primary cell cultures}

We studied 14 non-obese, non-smoking men (Table 1). Men were not using any medication, apart from one man

This work is licensed under a Creative Commons Attribution-NonCommercial-NoDerivatives 4.0 International License.ifica com at $04 / 26 / 2023 \quad 02: 43: 26$ AM 
Table 1 Clinical characteristics (mean \pm S.E.M.) of the male participants $(n=14)$.

Age (years)

BMI $\left(\mathrm{kg} / \mathrm{m}^{2}\right)$

Waist $(\mathrm{cm})$

Hip $(\mathrm{cm})$

Fasting plasma glucose $(\mathrm{mmol} / \mathrm{L})$

HbA1c (\%)

Serum cholesterol ( $\mathrm{mmol} / \mathrm{L})$

Serum triglyceride $(\mathrm{mmol} / \mathrm{L})$

Serum HDL cholesterol ( $\mathrm{mmol} / \mathrm{L})$

Serum LDL cholesterol ( $\mathrm{mmol} / \mathrm{L})$
Waist-to-hip ratio

$56 \pm 3$
$24.4 \pm 0.5$
$93 \pm 2$
$97 \pm 1$
$0.96 \pm 0.02$
$5.5 \pm 0.1$
$5.5 \pm 0.1$
$5.2 \pm 0.3$
$1.1 \pm 0.1$
$1.6 \pm 0.1$
$3.0 \pm 0.3$

who used simvastatin and alfuzosine. All had normal glucose tolerance, based on WHO criteria, in standard oral glucose tolerance test performed after an overnight fast. Muscle biopsy was collected after an overnight fast from vastus lateralis muscle under local anaesthesia $(10 \mathrm{mg} / \mathrm{mL}$ lidocaine hydrochloride). Satellite cells were isolated from the muscle biopsy by trypsinisation and maintained in high-glucose $(3150 \mathrm{mg} / \mathrm{L}, 17.5 \mathrm{mmol} / \mathrm{L})$ DMEM/F12 supplemented with $20 \%(\mathrm{v} / \mathrm{v}) \mathrm{FBS}, 1 \%(\mathrm{v} / \mathrm{v})$ penicillinstreptomycinand $1 \%(\mathrm{v} / \mathrm{v})$ amphotericin B, asdescribed (23). Primary myoblasts were purified from non-myogenic cells with CD56-labeled magnetic beads. To create mature myotubes, myoblasts were differentiated in low glucose (1000 mg/L, $5.6 \mathrm{mmol} / \mathrm{L})$ DMEM/F12 containing 2\% FBS $(\mathrm{v} / \mathrm{v})$ for 6-7 days prior experimental pre-treatments. For analyses performed with Seahorse $\mathrm{XF}^{\mathrm{e}} 96$ analyser, primary muscle cells were used as non-differentiated myoblasts.

\section{Preparation of statins}

Simvastatin was provided as powder in inactive lactoneform and was dissolved in DMSO. In order to activate lactone-form into acid-form simvastatin, the powder was dissolved in $0.1 \mathrm{M} \mathrm{NaOH}-\mathrm{EtOH}$ solution, incubated at $50^{\circ} \mathrm{C}$ for $2 \mathrm{~h}$, and $\mathrm{pH} 7$ was adjusted with $0.2 \mathrm{M} \mathrm{HCl}$, as described $(24,25)$.

\section{Pre-treatments with statins}

Differentiated myotubes were pre-treated for $48 \mathrm{~h}$ with a final concentration of $6 \mu \mathrm{g} / \mathrm{mL}(14.3 \mu \mathrm{M})$ lactone- and acidform simvastatin. This concentration was chosen based on the report by Yaluri et al. (20). As controls, myotubes or myoblasts were pre-treated with the corresponding solvent, $0.1 \%$ DMSO and EtOH-NaOH, for lactone- and acid-form simvastatin, respectively. In some experiments (Supplementary Fig. 1, see section on supplementary materials given at the end of this article), pravastatin was used with a final concentration of $13 \mu \mathrm{g} / \mathrm{mL}$ $(28.5 \mu \mathrm{M})(20)$. All pre-treatments were performed in low glucose DMEM containing 2\% (v/v) FBS and $4 \mathrm{mM}$ L-glutamine. After incubation for $46 \mathrm{~h}$, the pre-treatment was switched to starvation medium (with respective statin or control solution): low-glucose DMEM without FBS and supplemented with $0.5 \%(\mathrm{w} / \mathrm{v})$ fatty-acid free BSA and $4 \mathrm{mM}$ L-glutamine. Cells were serum-starved for $2 \mathrm{~h}$ before insulin stimulations. All incubations were performed at $+37^{\circ} \mathrm{C}$, in $5 \% \mathrm{CO}_{2}$ incubator.

\section{Glucose metabolism}

Glucose uptake was investigated in triplicate by measuring intracellular accumulation of $2-\left[1,2-{ }^{3} \mathrm{H}\right]$-deoxy-D-glucose (final specific activity $100 \mathrm{mCi} / \mathrm{mmol}$ ), as described $(26,27)$. In brief, statin-treated and serum-starved myotubes were stimulated with or without $100 \mathrm{nM}$ insulin in starvation media for $60 \mathrm{~min}$. Radioactive glucose tracer was added in glucose-free DMEM containing 0.5\% fatty-acid free BSA for $20 \mathrm{~min}$, without statins, and with or without insulin, followed by ice-cold PBS washes and freezing in $-20^{\circ} \mathrm{C}$. Non-specific glucose uptake was determined with cytochalasin $\mathrm{B}(50 \mu \mathrm{M})$. The cells were lysed in $0.4 \mathrm{M} \mathrm{NaOH}$ for $3 \mathrm{~h}$ and radioactivity detected in scintillation counter. Values were normalized to protein concentration measured with BCA assay. Data (in $\mathrm{pmol} / \mathrm{mg}$ protein/min) were normalized to the insulinstimulated glucose uptake (control) of each subject.

Glycogen synthesis was measured in triplicate, as described $(26,27)$, by detecting $\mathrm{D}-\left[{ }^{14} \mathrm{C}\right]$-glucose (final specific activity $0.18 \mu \mathrm{Ci} / \mu \mathrm{mol}$ ) incorporation into glycogen during 90 min of incubation with or without statins in the presence or absence of $100 \mathrm{nM}$ insulin added in starvation media. Glycogen was extracted from the cells lysed in $0.03 \%(\mathrm{w} / \mathrm{v})$ SDS, by boiling $30 \mathrm{~min}$ at $+100^{\circ} \mathrm{C}$ together with glycogen carrier (final concentration $2.5 \mathrm{mg} / \mathrm{mL}$ ) and precipitated with $94 \%$ ethanol followed by overnight incubation in $-20^{\circ} \mathrm{C}$. Precipitated glycogen was resolved in purified $\mathrm{H}_{2} \mathrm{O}$ and radioactivity detected in scintillation counter. Values were normalized to protein concentration measured with BCA assay. Data (in nmol/g protein/h) were normalized to the insulin-stimulated glycogen synthesis (control) of each subject.

Glycolysis and glycolytic capacity were analysed by measuring extracellular acidification rate (ECAR) in myoblasts with Seahorse $\mathrm{XF}^{\mathrm{e}} 96$ analyser (Seahorse Bioscience, a part of Agilent Technologies) by using XF Glycolysis Stress Test Kit, according to manufacturer's 
instructions. Briefly, 20,000 cells/well were plated on XF96-well cell culture microplates 3 days before the assay, and on the next day pre-treated with $6 \mu \mathrm{g} / \mathrm{mL}$ simvastatin (acid- and lactone-forms separately) or with their respective controls for $48 \mathrm{~h}$, as described previously. The pre-treatment media was replaced with glucose-free $\mathrm{XF}$ Assay media and equilibrated for $60 \mathrm{~min}$ at $37^{\circ} \mathrm{C}$ in a $\mathrm{CO}_{2}$-free incubator before being transferred to the $\mathrm{XF}^{\mathrm{e} 96}$ analyser for the assay. During the assay, $10 \mathrm{mM}$ glucose, $1 \mu \mathrm{M}$ oligomycin and $50 \mathrm{mM}$ 2-DG were injected sequentially to measure the glycolysis, glycolytic capacity and non-glycolytic acidification of the cells, respectively. Nuclear fluorescent stain Hoechst 33342 was added in the last injection to measure in situ nuclei count with BioTek Cytation 5 imager using the Montage function in the Gen5 software (28). Raw data were normalized to nuclei count and scaled up to 20000 cells using the scale factor feature in Seahorse Wave software, as described in Kam et al. (29).

\section{Protein extraction and Western blot analysis}

Pre-treated myotubes, with or without insulinstimulation (100 $\mathrm{nM}$ for $10 \mathrm{~min})$, were lysed in NP40-lysis buffer $(10 \mathrm{mM}$ Tris, $150 \mathrm{mM} \mathrm{NaCl}, 7 \mathrm{mM}$ EDTA and $0.5 \%$ NP-40) supplemented with protease and phosphatase inhibitors, sonicated and spun at $14,000 \boldsymbol{g}$ for $15 \mathrm{~min}$ at $+4^{\circ} \mathrm{C}$. Protein concentration was determined with BCA Protein Assay kit. Proteins were separated by 10\% SDS-PAGE, transferred to PVDF membrane by semi-dry electroblotting (Bio-Rad) and blocked with 5\%(w/v) milk - 0.1\% (v/v) Tween-TBS (TBST). Phosphorylated proteins were detected from membranes incubated with pAkt-Ser ${ }^{473}$, pAkt-Thr ${ }^{308 \text {, }}$ pAS160-Thr ${ }^{642}$, pGSK3 $\beta-$ Ser $^{9}$ and pAMPK-Thr ${ }^{172}$ primary antibodies at a dilution of 1:1000 in 5\% (w/v) BSA-TBST overnight at $+4^{\circ} \mathrm{C}$. Primary antibodies were probed with HRP-conjugated secondary antibody and visualized by enhanced chemiluminescence. Total target proteins were detected with corresponding antibodies after treating the membranes with stripping buffer $(62.5 \mathrm{mM}$ Tris $\mathrm{pH}$ $6.8,2 \%(\mathrm{w} / \mathrm{v})$ SDS, $0.7 \%(\mathrm{v} / \mathrm{v}) \beta$-mercaptoethanol) for $45 \mathrm{~min}$ in $+45^{\circ} \mathrm{C}$ shaker. Intensities of the proteins of interest were quantified using Fiji software (30) or Image Lab 5.1 software (Bio-Rad). Values of the intensities of the phosphorylated proteins were normalized to the intensity of their corresponding total protein. Data were normalized to the insulin-stimulated control sample of each subject.

\section{Mitochondrial oxygen consumption}

Mitochondrial respiration was analyzed by measuring oxygen consumption rate (OCR) with Seahorse XFe96 analyzer by using XF Mito Stress Test Kit, according to manufacturer's instructions. Seeding the cells and all the pre-treatments were performed as described in the glycolysis assay. The pre-treatment media was replaced with XF Assay media supplemented with $5 \mathrm{mM}$ glucose and equilibrated for $60 \mathrm{~min}$ at $37^{\circ} \mathrm{C}$ in a $\mathrm{CO}_{2}$-free incubator prior to the assay. During the assay, basal oxygen consumption rate (OCR) was measured, followed by sequential injections of $1 \mathrm{mM}$ oligomycin, $1.5 \mu \mathrm{M}$ FCCP and $0.5 \mu \mathrm{M}$ Rotenone and Antimycin C, to measure ATP production and proton leakage, maximal respiration and spare respiratory capacity, and finally non-mitochondrial respiration, respectively. Raw data were normalized as described in glycolysis assay.

\section{Statistical analyses}

Data are presented as mean \pm S.E.M. Statistical analyses were performed using GraphPad Prism (version 6.0h for Mac OS X). One- and two-way ANOVAs with repeated measurements followed by Sidak's post hoc test for multiple comparisons, were used to analyze data. $P<0.05$ was considered statistically significant.

\section{Results}

\section{Lactone-form simvastatin increases glucose uptake}

Primary human myotubes were treated for $48 \mathrm{~h}$ with $6 \mu \mathrm{g} / \mathrm{mL}(14.3 \mu \mathrm{mol} / \mathrm{L})$ either lactone- or acid-forms of simvastatin. Exposure to lactone-form simvastatin led to a significant increase in basal $(1.50$-fold, $P<0.0001)$ and insulin-stimulated (1.40-fold, $P<0.0001)$ glucose uptake (Fig. 1A). Acid-form simvastatin did not affect glucose uptake (Fig. 1B). As the diabetogenic effect of hydrophilic pravastatin has been shown to be far less than with simvastatin (9), we next tested if pravastatin impacts glucose uptake. Exposure of myotubes for $48 \mathrm{~h}$ to $13 \mu \mathrm{g} / \mathrm{mL}$ $(28.5 \mu \mathrm{mol} / \mathrm{L})$ pravastatin did not affect basal or insulinstimulated glucose uptake (Supplementary Fig. 1A).

\section{Lactone-form simvastatin increases, whereas acid-form simvastatin decreases glycogen synthesis}

Exposure of primary human myotubes to lactone-form simvastatin led to a 1.51-fold increase in basal glucose

This work is licensed under a Creative Commons Attribution-NonCommercial-NoDerivatives 4.0 International License ifica com at $04 / 26 / 2023 \quad 02: 43: 26$ AM 
B

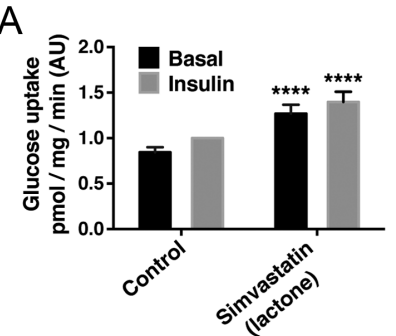

C

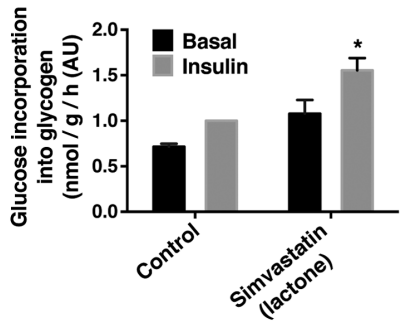

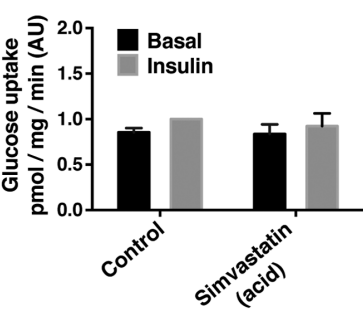

D

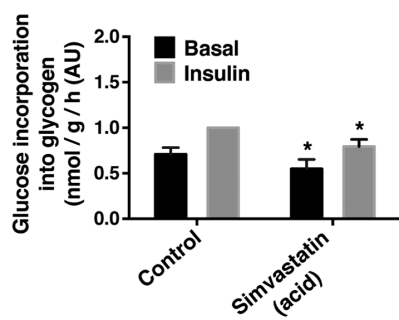

Figure 1

Glucose uptake (A and B) and glucose incorporation into glycogen ( $C$ and D) were measured using radioactive tracers. The effects of lactone- ( $A$ and C) and acid-form ( $B$ and $D$ ) simvastatin on glucose metabolism in primary human myotubes, in basal or insulin-stimulated conditions. Glucose uptake data (in pmol/mg/min) are expressed as mean \pm S.E.M. from 11 (lactone) and 9 (acid) men. Glycogen synthesis data (in $\mathrm{nmol} / \mathrm{g} / \mathrm{h}$ ) are expressed as mean \pm S.E.M. from five (for both lactone and acid) men. * $P<$ 0.05 and $* * \star * P<0.0001$ vs. respective control, two-way ANOVA with repeated measurements, Sidak's post hoc test, AU, arbitrary units.

incorporation into glycogen. However, this effect did not reach statistical significance $(P=0.0606)$. Exposure of myotubes to lactone-form simvastatin led to a significant 1.55 -fold increase $(P=0.0150)$ in insulin-stimulated glucose incorporation into glycogen (Fig. 1C). In contrast to lactone-form, exposure to acid-form simvastatin led to a significant decrease in both basal $(P=0.0344)$ and insulin-stimulated $(P=0.0148)$ glucose incorporation into glycogen (Fig. 1D). Pravastatin exposure increased basal $(P=0.0035)$ and did not affect insulin-stimulated glycogen synthesis (Supplementary Fig. 1B).

\section{Lactone-form simvastatin has a more profound effect on insulin signalling than acid- form simvastatin}

Exposure of primary human myotubes to lactone-form simvastatin led to a non-significant reduction $(P=0.0590)$ in insulin-stimulated phosphorylation of Akt-Ser ${ }^{473}$ (Fig. $2 \mathrm{~A})$ and to a significant reduction $(P=0.0303)$ in insulin-stimulated phosphorylation of Akt-Thr ${ }^{308}$ (Fig. 2B). However, exposure to lactone-form simvastatin led to increased $(P=0.0085)$ insulin-stimulated phosphorylation of AS160 (Fig. 2C) and increased basal $(P=0.0066)$ and
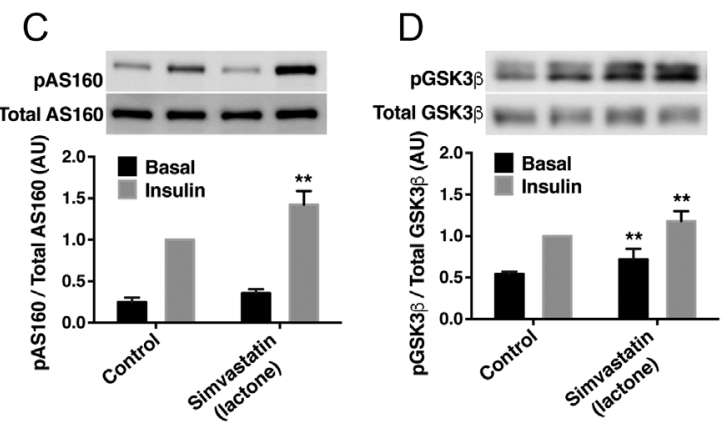

\section{G}

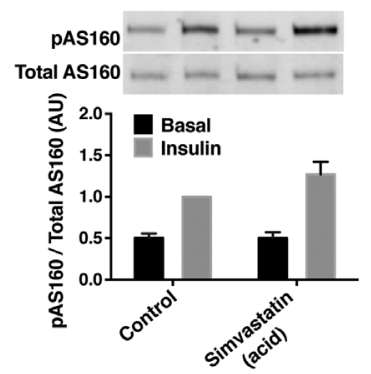

$\mathrm{H}$

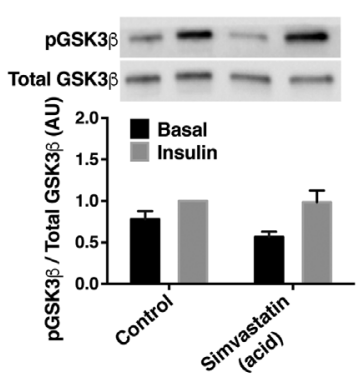

Figure 2

Activation of insulin signalling pathway. Western blot analysis showing the effect of lactone- (A, B, C and D) and acid-form (E, F, G and H) simvastatin in primary human myotubes, with or without insulin-stimulation. Representative blots and quantification of phosphorylated (p) Akt-Ser ${ }^{473}(A, E), p A k t-$ $\operatorname{Thr}^{308}(B, F), p^{2} 160-\operatorname{Thr}^{642}(C, G)$, and pGSK3 $\beta-S e r{ }^{9}(D, H)$, and of their respective total proteins. Data are expressed as mean \pm S.E.M. from five men, except $n=9$ for pAS160-Thr ${ }^{642}$ (C) and $n=7$ for $p G S K 3 \beta-$ Ser $^{9}$ (D) in lactone-treated group. $* P<0.05$ and $* * P<0.01$ vs respective control, two-way ANOVA with repeated measurements, Sidak's post hoc test, AU, arbitrary units.

https://ec.bioscientifica.com https://doi.org/10.1530/EC-20-0444 (c) 2020 The authors Published by Bioscientifica Ltd

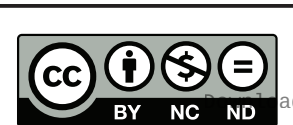

This work is licensed under a Creative Commons Attribution-NonCommercial-NoDerivatives 4.0 elnternationab dicense.ifica.com at 04/26/2023 02:43:26AM 
insulin-stimulated $(P=0.0060)$ phosphorylation of GSK3 $\beta$ (Fig. 2D). Exposure of primary human myotubes to acidform simvastatin led to reduced $(P=0.0438)$ insulinstimulated phosphorylation of Akt-Thr ${ }^{308}$ (Fig. 2F), whereas phosphorylation of Akt-Ser ${ }^{473}$ (Fig. 2E), AS160 (Fig. 2G) or GSK3 $\beta$ (Fig. 2H) was not affected by acid-form simvastatin.

\section{Lactone- and acid-form simvastatin reduce glycolysis and mitochondrial respiration, and lactone-form simvastatin activates AMPK}

Exposure of human myoblasts to lactone- or acid-form simvastatin led to a profound reduction in both glycolysis ( $P=0.0004$ for lactone-, and $P=0.0004$ for acid-form) and glycolytic capacity $(P=0.0009$ for lactone-, and $P=0.0004$ for acid-form) (Fig. 3). Exposure to either form simvastatin led to a reduction also in mitochondrial oxygen consumption ( $P=0.0073$ for lactone-, and $P=0.0001$ for acid-form) and ATP production $(P=0.0002$ for lactone-, and $P<0.0001$ for acid-form) (Fig. 4). Inhibition of mitochondrial ATP production leads to an increase in cellular AMP to ATP ratio, which activates AMPK, a sensor of cellular energy status (31). Thus, we next analyzed the phosphorylation of AMPK. Exposure of primary human myotubes to lactone-form simvastatin led to a significant increase in basal $(P=0.0075)$ and insulin-stimulated $(P=0.0030)$ AMPK phosphorylation at $\mathrm{Thr}^{172}$ (Fig. 5A). Acid-form simvastatin did not affect AMPK phosphorylation (Fig. 5B).

\section{Discussion}

Statins are widely used to lower plasma cholesterol levels. They inhibit the mevalonate pathway that mediates cholesterol synthesis $(2,3,4)$. While use of statins effectively reduces the risk of atherosclerotic events, several studies have demonstrated that statin treatment may have adverse effects including myotoxicity, impaired insulin sensitivity and increased risk for type 2 diabetes $(6,12,14,32)$. Direct molecular mechanisms leading to statin-induced myotoxicity and insulin resistance in skeletal muscle are yet to be comprehensively reported. However, one issue may relate to the lipophilic nature of certain statins, such as the lactone-form simvastatin, which are more prone to cause myotoxicity (19). Lactoneform simvastatin has also been suggested to induce insulin resistance by suppressing insulin signalling and GLUT4 expression (20).
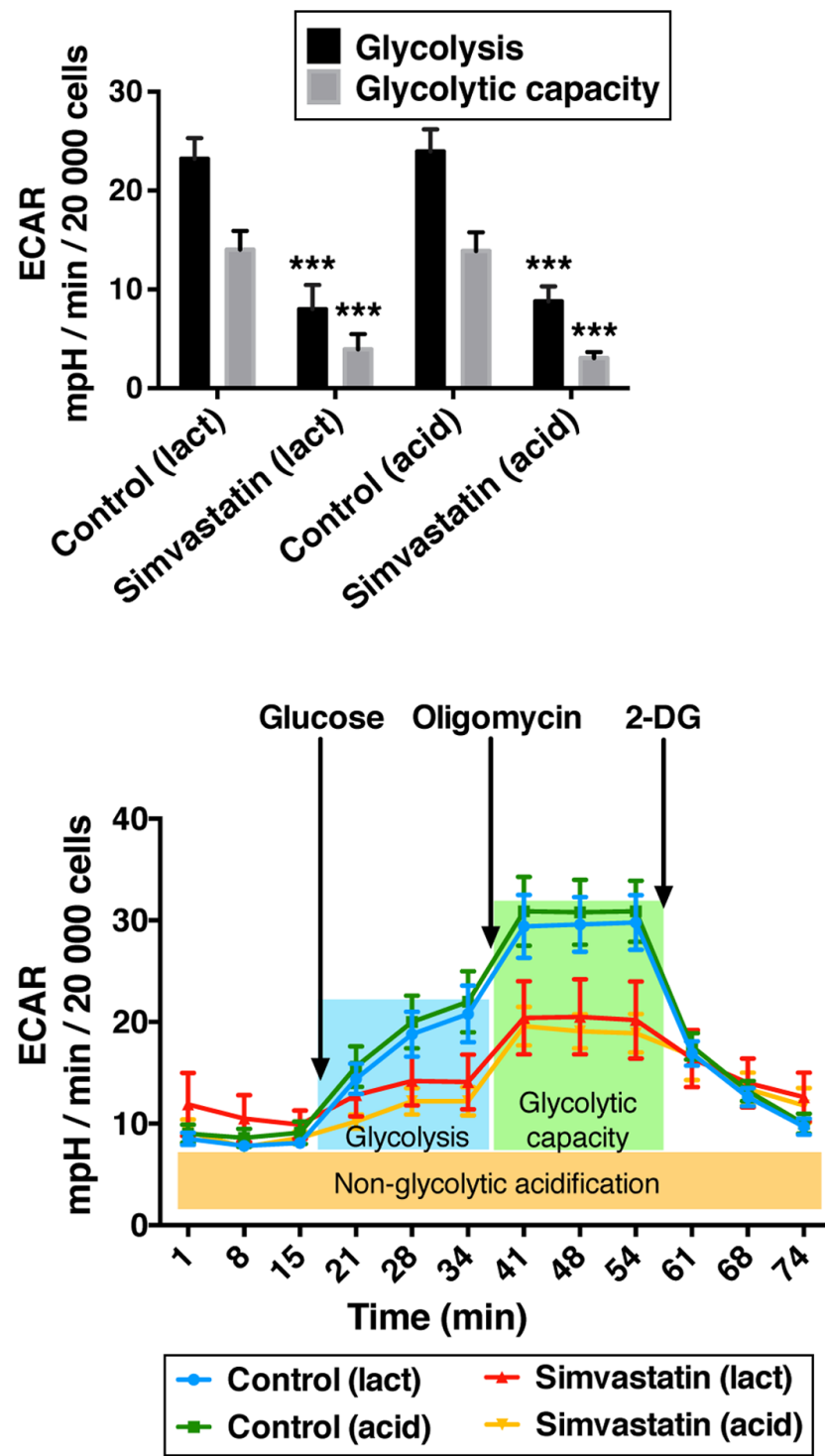

Figure 3

Glycolysis and glycolytic capacity in response to pre-exposure to lactone- and acid-form simvastatin were measured by detecting extracellular acidification rate (ECAR) in primary human myoblasts with Seahorse analyzer. Data (in $\mathrm{mpH} / \mathrm{min} / 20,000$ cells) are expressed as mean \pm S.E.M. from six men. ${ }^{\star \star \star} P<0.001$ vs respective control, one-way ANOVA with repeated measurements, Sidak's post hoc test.

Here, we compared the effects of lactone- and acidforms simvastatin on glucose metabolism in primary human skeletal muscle cells. To the best of our knowledge, the effects of simvastatin on insulin-stimulated glucose metabolism have not been previously reported in human skeletal muscle cells. In our study, lactone-form simvastatin increased both basal and insulin-simulated glucose uptake. This finding was quite unexpected and in contradiction with previous data using L6 (rat) or $\mathrm{C} 2 \mathrm{C} 12$ (mouse) myotubes, where both basal and

This work is licensed under a Creative Commons Attribution-NonCommercial-NoDerivatives 4.0 Internationab ficense.ifica . com at $04 / 26 / 2023 \quad 02: 43: 26$ AM 

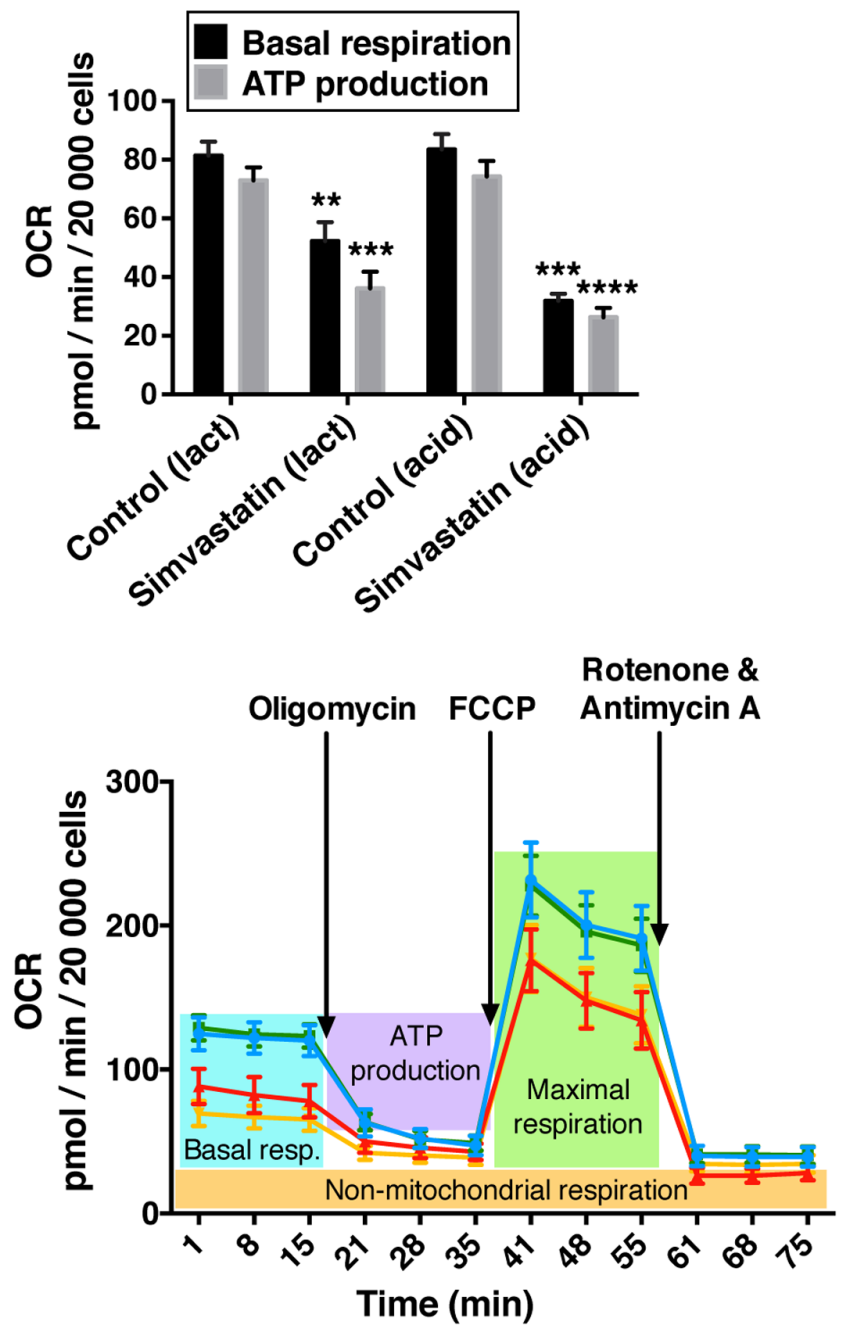

$\rightarrow$ Control (lact) $\quad-$ Simvastatin (lact)
- Control (acid) $\quad-$ Simvastatin (acid)

Figure 4

Mitochondrial respiration and ATP production in response to preexposure to lactone- and acid-form simvastatin were measured by detecting oxygen consumption rate (OCR) in primary human myoblasts with Seahorse analyzer. Data (in pmol/min/20,000 cells) are expressed as mean \pm S.E.M. from four men. $* * P<0.01, * * * P<0.001$ and $* * * * P<0.0001$ vs respective control, one-way ANOVA with repeated measurements, Sidak's post hoc test.

insulin-stimulated glucose uptake were reduced by lactone-form simvastatin $(20,21)$. While there may be differences in metabolic responses between rodentderived and human muscle cells, simvastatin also reduced basal glucose uptake in human myotubes (33). The reason for these apparently contradictory results is not obvious. However, we observed that insulin-stimulated glycogen synthesis was also increased in response to lactone-form simvastatin, with a tendency for an increase also in basal glycogen synthesis. Thus, these data are consistent with
A

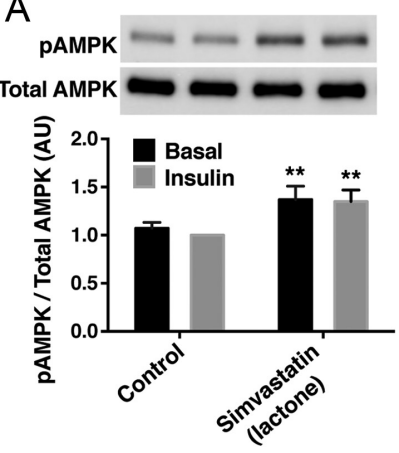

B

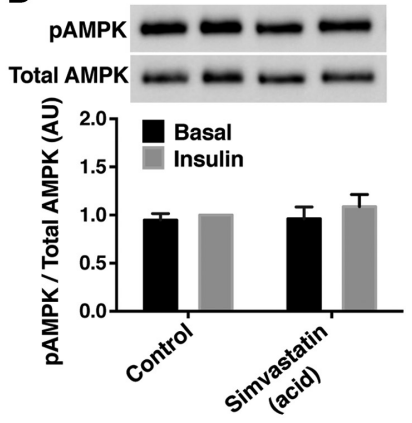

Figure 5

Activation of AMP-activated protein kinase (AMPK). Western blot analysis showing the effect of lactone- (A) and acid-form (B) simvastatin in primary human myotubes. The representative blots and quantification of phosphorylated AMPK-Thr ${ }^{172}$ and total AMPK. Data are expressed as mean \pm S.E.M. from nine (lactone) and five (acid) men, $* * P<0.01$ vs respective control, two-way ANOVA with repeated measurements, Sidak's post hoc test, AU, arbitrary units.

the observed activation of glucose uptake in response to lactone-form simvastatin. Exposure of human muscle cells to acid-form simvastatin has previously been reported to reduce basal glucose uptake (32), whereas in our study acid-form simvastatin did not affect glucose uptake. This discrepancy may be related to methodological differences to assay glucose uptake, which was detected by glucose analogue 6-NBDG by Nowis et al. (32) whereas we assayed glucose uptake with radiolabelled 2-deoxyglucose. However, we observed an inhibition of both basal and insulin-stimulated glycogen synthesis by acid-form simvastatin. Taken together, our data suggest different metabolic effects for acid- and lactone-forms of simvastatin during $48 \mathrm{~h}$ exposure. An inhibition of basal and insulin-stimulated glycogen synthesis by active acidform simvastatin may contribute to a reduction in insulin sensitivity observed with simvastatin treatment (6).

Metabolic actions were accompanied by changes in insulin signalling cascade, as insulin-stimulated phosphorylation of AS160 and GSK3 $\beta$ were upregulated with lactone-, but not with acid-form simvastatin. Interestingly, the activation of both Akt sites at $\mathrm{Ser}^{473}$ or $\mathrm{Thr}^{308}$ were inhibited with lactone-form simvastatin, suggesting an Akt-independent mechanism for phosphorylation of AS160 and GSK3 $\beta$ with lactone-form simvastatin.

In order to get more detailed insight into the glucose metabolism in terms of energy production, we determined the rate of glycolysis and mitochondrial respiration, both of which produce ATP. After $48 \mathrm{~h}$ exposure of myoblasts to both forms of simvastatin, the rate of glycolysis and mitochondrial respiration were measured in real-time

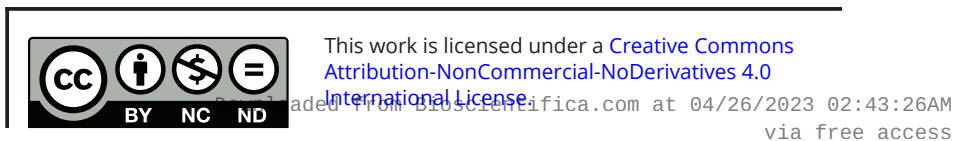


with the Seahorse analyzer. Either form of simvastatin led to a profound reduction in both glycolysis and glycolytic capacity, indicating that simvastatin-treated cells had diminished capability to catabolize glucose. These findings are consistent with a recent study where simvastatin reduced glycolysis and glycolytic capacity in neuroblastoma cells (34). Statins have been implicated with impaired mitochondrial function in several studies $(16,17,35)$. Lactone-form statins, including lactone-form simvastatin, have especially been shown to be more potent in inducing cytotoxicity and reducing mitochondrial respiration and ATP production rate, when compared to their corresponding acid-forms (22). Acid-form simvastatin also reduces ATP content in C2C12 myotubes (17). Our findings are in agreement with the idea of overall negative impact of statins on mitochondrial function, as exposure to both lactone and acid-form of simvastatin led to a decrease in mitochondrial oxygen consumption and ATP production.

The observed increase in glucose uptake in response to lactone-form simvastatin may be a consequence of increased cellular stress and AMPK activation. Reduced mitochondrial ATP production leads to an increase in cellular AMP to ATP ratio. This activates AMPK, a sensor of cellular energy status (31). Indeed, we observed that exposure of primary human myotubes to lactone-form simvastatin led to a significant increase in AMPK-Thr ${ }^{172}$ phosphorylation. This was not observed with acidform simvastatin, which may be related to the more profound inhibition of mitochondrial respiration and ATP production with lactone-form simvastatin (22). Even though both forms of simvastatin reduced mitochondrial respiration and ATP production in our study, it is possible that differences in their inhibitory potency may not have been revealed by our experimental set-up. AMPK directly phosphorylates AS160 $(36,37)$ and increases glucose uptake in an insulin-independent fashion (38). AS160 phosphorylation was increased in myotubes exposed to lactone-form simvastatin even if the Akt phosphorylation was blunted. These data suggest an Aktindependent mechanism for increased glucose uptake in response to lactone-form simvastatin, which may be AMPK-mediated. As glucose uptake was increased and glucose oxidation markedly diminished, glucose fluxes were directed towards non-oxidative glucose disposal in muscle cells treated with lactone-form simvastatin. The increase in glucose incorporation into glycogen may have been facilitated by increased phosphorylation of GSK3 $\beta$ in response to lactone-form simvastatin. As the activation of Akt was reduced, these data suggest an Akt-independent phosphorylation for GSK3 $\beta$. One possible mechanism may be related to activation of protein kinase C (PKC) (39), especially its $\alpha, \beta 1$ and $\gamma$ isoforms (40), which are known to phosphorylate GSK3 $\beta$. A schematic presentation of the effects of lactone-form simvastatin on glucose metabolism and signalling events in primary human skeletal muscle cells is given in Fig. 6.

The limitation of the current study is that we investigated in detail the effects of only one of the statins used as cholesterol-lowering drug. Inclusion of other lipophilic statins, such as lovastatin or atorvastatin (10), could have improved the interpretations of the effects observed with simvastatin. However, in some experiments we included hydrophilic and clinically far less diabetogenic pravastatin, which did not affect glucose uptake or insulinstimulated glycogen synthesis. This strengthens our observations regarding simvastatin. The concentration of the simvastatin used in this study was $6 \mu \mathrm{g} / \mathrm{mL}$ and the concentration of pravastatin was $13 \mu \mathrm{g} / \mathrm{mL}$, which are in line with those used in other in vitro studies $(19,20,22$, 33). Plasma concentrations for simvastatin and pravastatin after oral intake are in the scale of nanograms per milliliter $(18,41)$. Thus, the concentrations used usually in in vitro experiments are substantially higher than those reached in vivo, and are at supraphysiological concentrations to provide a maximal stimulus during a short-term exposure. The time and pH-dependent conversion of the lactoneform simvastatin to the corresponding hydroxy acid in cell culture conditions at $37^{\circ} \mathrm{C}$ has been observed to be substantial after 24-48 h incubation (42). However, the effect of lactone-form simvastatin exposure for $48 \mathrm{~h}$ on

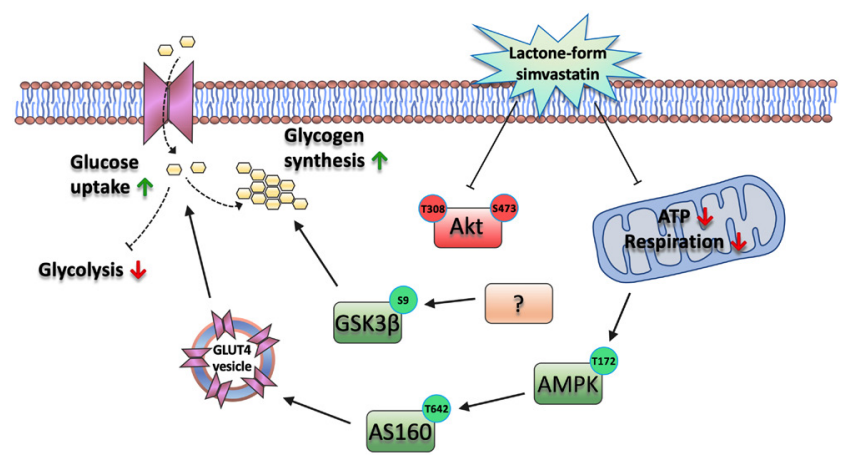

Figure 6

Schematic presentation of the effects of lactone-form simvastatin on glucose metabolism and signalling events in primary human skeletal muscle cells. Down- and upregulated metabolic and signalling events are indicated in red and green color, respectively. Dashed line indicates the metabolic action. Akt, protein kinase B; AMPK, adenosine monophosphate (AMP)-activated protein kinase; AS160, Akt-substrate 160 kDa; ATP, adenosine triphosphate; GLUT4, glucose transporter 4; GSK3 $\beta$, glycogen synthase kinase $3 \beta$. 
glucose uptake and glycogen synthesis was completely different to acid-form in our studies, suggesting that even lower amount of lactone-form simvastatin is sufficient to elicit different responses on glucose uptake and glycogen synthesis as compared to acid-form. Muscle cell cultures had been established only from men, which is also a limitation. As, for example, estrogens promote insulin sensitivity (43), it would be interesting to investigate in the future if gender would affect the responses of muscle cells to statins. Another limitation of the study is that glycolysis and mitochondrial respiration were studied in myoblasts, and in other experiments differentiated myotubes were used. While myoblasts and myotubes may exhibit differences in their metabolic responses (26), our observation of reduced mitochondrial respiration in simvastatin-treated human myoblasts is in good agreement with Kwak et al. (35) who observed reduced mitochondrial respiration in simvastatin-treated human myotubes. Thus, simvastatin inhibits mitochondrial respiration both in myoblasts and myotubes. The overall strength of our study is the use of biological replicates for the comprehensive and complementary approaches to investigate glucose metabolism, as methods included determination of glucose uptake, glycogen synthesis and glycolysis.

In conclusion, our data indicate that lactone- and acidforms of simvastatin exhibit differential effects on nonoxidative glucose metabolism as lactone-form increases and acid-form impairs glucose storage into glycogen, suggesting impaired insulin sensitivity in response to acidform simvastatin. Both forms of simvastatin demonstrate similar inhibitory effect on oxidative glucose metabolism and energy production in human skeletal muscle cells. Taken together, these effects may contribute to increased risk of myotoxicity and type 2 diabetes that has been observed with simvastatin use $(6,12)$.

\section{Supplementary materials}

This is linked to the online version of the paper at https://doi.org/10.1530/ EC-20-0444.

\section{Declaration of interest}

The authors declare that there is no conflict of interest that could be perceived as prejudicing the impartiality of the research reported.

\section{Funding}

This study has been supported by grants to $\mathrm{H}$ A K from Academy of Finland (grant no. 258753), Diabetes Wellness Sverige (grant no 598174), Finnish Diabetes Research Foundation, Finska Läkaresällskapet, Finnish Medical Foundation, Helsinki University Central Hospital (funding from hospital administration and governmental subsidy for research), Jalmari and Rauha Ahokas Foundation, Laboratoriolääketieteen edistämissäätiö sr, Liv och Hälsa Foundation, Novo Nordisk Foundation, and Sigrid Juselius Foundation. S M has received support from Doctoral School of Health Sciences (Doctoral Programme in Clinical Research) of University of Helsinki, Finnish Diabetes Research Foundation, and Finska Läkaresällskapet.

\section{Ethics approval and consent to participate}

The study was approved by the ethical committee of Helsinki University Central Hospital (261/13/03/01/2008) and was conducted according to the standards of the Declaration of Helsinki as revised in 2008. Written informed consent was obtained from the subjects before participation.

\section{Author contribution statement}

S M, N D, Y H N, M L and H A K designed the study. S M, N D, Y H N, P K and $\mathrm{H} \mathrm{A} \mathrm{K}$ acquired the data. S M, N D and H A K analyzed and interpreted the data. S M and $\mathrm{H} A \mathrm{~K}$ drafted the article, which was reviewed and edited by $\mathrm{N}$ $\mathrm{D}, \mathrm{YH} \mathrm{N}, \mathrm{P} \mathrm{K}$ and $\mathrm{M} \mathrm{L}$. H A K supervised the study and acquired the funding.

\section{Acknowledgement}

The authors thank all the volunteers who participated in the study.

\section{References}

1 Evans M \& Rees A. Effects of HMG-CoA reductase inhibitors on skeletal muscle: are all statins the same? Drug Safety $2002 \mathbf{2 5}$ 649-663. (https://doi.org/10.2165/00002018-200225090-00004)

2 US Preventive Services Task Force; Bibbins-Domingo K, Grossman DC, Curry SJ, Davidson KW, Epling JW, García FAR, Gillman MW, Kemper AR, Krist AH, et al. Statin use for the primary prevention of cardiovascular disease in adults: US Preventive Services Task Force Recommendation Statement. JAMA 2016316 1997-2007. (https://doi.org/10.1001/jama.2016.15450)

3 Ryan A, Heath S \& Cook P. Primary prevention with statins for older adults. BMJ 2018362 k3695. (https://doi.org/10.1136/bmj.k3695)

4 Spector R \& Snapinn SM. Statins for secondary prevention of cardiovascular disease: the right dose. Pharmacology 201187 63-69. (https://doi.org/10.1159/000322999)

5 Maki KC, Dicklin MR \& Baum SJ. Statins and diabetes. Endocrinology and Metabolism Clinics of North America 201645 87-100. (https://doi. org/10.1016/j.ecl.2015.09.006)

6 Cederberg H, Stancakova A, Yaluri N, Modi S, Kuusisto J \& Laakso M. Increased risk of diabetes with statin treatment is associated with impaired insulin sensitivity and insulin secretion: a 6 year follow-up study of the METSIM cohort. Diabetologia 201558 1109-1117. (https://doi.org/10.1007/s00125-015-3528-5)

7 Sukhija R, Prayaga S, Marashdeh M, Bursac Z, Kakar P, Bansal D, Sachdeva R, Kesan SH \& Mehta JL. Effect of statins on fasting plasma glucose in diabetic and nondiabetic patients. Journal of Investigative Medicine 200957 495-499. (https://doi.org/10.2310/ JIM.0b013e318197ec8b)

8 Bellia A, Rizza S, Lombardo MF, Donadel G, Fabiano R, Andreadi K, Quon MJ, Sbraccia P, Federici M, Tesauro M, et al. Deterioration of glucose homeostasis in type 2 diabetic patients one year after beginning of statins therapy. Atherosclerosis 2012223 197-203. (https://doi.org/10.1016/j.atherosclerosis.2012.04.015)

9 Navarese EP, Buffon A, Andreotti F, Kozinski M, Welton N, Fabiszak T, Caputo S, Grzesk G, Kubica A, Swiatkiewicz I, et al. Meta-analysis of impact of different types and doses of statins on new-onset diabetes 
mellitus. American Journal of Cardiology 2013111 1123-1130. (https://doi.org/10.1016/j.amjcard.2012.12.037)

10 Ward NC, Watts GF \& Eckel RH. Statin toxicity. Circulation Research 2019124 328-350. (https://doi.org/10.1161/ CIRCRESAHA.118.312782)

11 Neuvonen PJ, Niemi M \& Backman JT. Drug interactions with lipid-lowering drugs: mechanisms and clinical relevance. Clinical Pharmacology and Therapeutics 200680 565-581. (https://doi. org/10.1016/j.clpt.2006.09.003)

12 Bruckert E, Hayem G, Dejager S, Yau C \& Begaud B. Mild to moderate muscular symptoms with high-dosage statin therapy in hyperlipidemic patients - the PRIMO study. Cardiovascular Drugs and Therapy 200519 403-414. (https://doi.org/10.1007/s10557-0055686-z)

13 Larsen S, Vigelso A, Dandanell S, Prats C, Dela F \& Helge JW. Simvastatin-induced insulin resistance may be linked to decreased lipid uptake and lipid synthesis in human skeletal muscle: the LIFESTAT study. Journal of Diabetes Research 201820189257874. (https://doi.org/10.1155/2018/9257874)

14 Phillips PS, Haas RH, Bannykh S, Hathaway S, Gray NL, Kimura BJ, Vladutiu GD \& England JDF. Statin-associated myopathy with normal creatine kinase levels. Annals of Internal Medicine 2002137 581-585. (https://doi.org/10.7326/0003-4819-137-7-20021001000009)

15 Bonifacio A, Sanvee GM, Bouitbir J \& Krahenbuhl S. The AKT/mTOR signaling pathway plays a key role in statin-induced myotoxicity. Biochimica et Biophysica Acta 20151853 1841-1849. (https://doi. org/10.1016/j.bbamcr.2015.04.010)

16 Mullen PJ, Zahno A, Lindinger P, Maseneni S, Felser A, Krahenbuhl S $\&$ Brecht K. Susceptibility to simvastatin-induced toxicity is partly determined by mitochondrial respiration and phosphorylation state of Akt. Biochimica and Biophysica Acta 20111813 2079-2087. (https://doi.org/10.1016/j.bbamcr.2011.07.019)

17 Sanvee GM, Bouitbir J \& Krahenbuhl S. Insulin prevents and reverts simvastatin-induced toxicity in C2C12 skeletal muscle cells. Scientific Reports 20199 7409. (https://doi.org/10.1038/s41598-019-43938-5)

18 Backman JT, Kyrklund C, Kivisto KT, Wang JS \& Neuvonen PJ. Plasma concentrations of active simvastatin acid are increased by gemfibrozil. Clinical Pharmacology and Therapeutics 200068 122-129. (https://doi.org/10.1067/mcp.2000.108507)

19 Skottheim IB, Gedde-Dahl A, Hejazifar S, Hoel K \& Asberg A. Statin induced myotoxicity: the lactone forms are more potent than the acid forms in human skeletal muscle cells in vitro. European Journal of Pharmaceutical Sciences 200833 317-325. (https://doi.org/10.1016/j. ejps.2007.12.009)

20 Yaluri N, Modi S \& Kokkola T. Simvastatin induces insulin resistance in L6 skeletal muscle myotubes by suppressing insulin signaling, GLUT4 expression and GSK-3 $\beta$ phosphorylation. Biochemical and Biophysical Research Communications 2016480 194-200. (https://doi. org/10.1016/j.bbrc.2016.10.026)

21 Li W, Liang X, Zeng Z, Yu K, Zhan S, Su Q, Yan Y, Mansai H, Qiao W, Yang Q, et al. Simvastatin inhibits glucose uptake activity and GLUT4 translocation through suppression of the IR/IRS-1/Akt signaling in C2C12 myotubes. Biomedicine and Pharmacotherapy 201683 194-200. (https://doi.org/10.1016/j.biopha.2016.06.029)

22 Schirris TJ, Renkema GH, Ritschel T, Voermans NC, Bilos A, van Engelen BG, Brandt U, Koopman WJ, Beyrath JD, Rodenburg RJ, et al. Statin-induced myopathy is associated with mitochondrial complex III inhibition. Cell Metabolism 201522 399-407. (https:// doi.org/10.1016/j.cmet.2015.08.002)

23 Mäkinen S, Nguyen YH, Skrobuk P \& Koistinen HA. Palmitate and oleate exert differential effects on insulin signalling and glucose uptake in human skeletal muscle cells. Endocrine Connections 20176 331-339. (https://doi.org/10.1530/EC-17-0039)

24 McKay A, Leung BP, McInnes IB, Thomson NC \& Liew FY. A novel anti-inflammatory role of simvastatin in a murine model of allergic asthma. Journal of Immunology 2004172 2903-2908. (https://doi. org/10.4049/jimmunol.172.5.2903)

25 Dong W, Vuletic S \& Albers JJ. Differential effects of simvastatin and pravastatin on expression of Alzheimer's disease-related genes in human astrocytes and neuronal cells. Journal of Lipid Research 2009 50 2095-2102. (https://doi.org/10.1194/jlr.M900236-JLR200)

26 Al-Khalili L, Chibalin AV, Kannisto K, Zhang BB, Permert J, Holman GD, Ehrenborg E, Ding VD, Zierath JR \& Krook A. Insulin action in cultured human skeletal muscle cells during differentiation: assessment of cell surface GLUT4 and GLUT1 content. Cellular and Molecular Life Sciences 200360 991-998. (https://doi.org/10.1007/ s00018-003-3001-3)

27 Skrobuk P, von Kraemer S, Semenova MM, Zitting A \& Koistinen HA. Acute exposure to resveratrol inhibits AMPK activity in human skeletal muscle cells. Diabetologia 201255 3051-3060. (https://doi. org/10.1007/s00125-012-2691-1)

28 Kam Y, Jastromb N, Clayton J, Held P \& Dranka BP. Normalization of Agilent Searhorse XF Data by In-Situ Cell Counting Using a BioTek Cytation 5. Agilent Technologies Inc., 2017.

29 Kam Y, Rogers G, Jastromb N \& Dranka B. Methods and Strategies for Normalizing XF Metabolic Data to Cellular Parameters. Technical Overview. Agilent Technologies, Inc., 2018.

30 Schindelin J, Arganda-Carreras I, Frise E, Kaynig V, Longair M, Pietzsch T, Preibisch S, Rueden C, Saalfeld S, Schmid B, et al. Fiji: an open-source platform for biological-image analysis. Nature Methods 20129 676-682. (https://doi.org/10.1038/nmeth.2019)

31 Towler MC \& Hardie DG. AMP-activated protein kinase in metabolic control and insulin signaling. Circulation Research 2007100 328-341. (https://doi.org/10.1161/01. RES.0000256090.42690.05)

32 Nowis D, Malenda A, Furs K, Oleszczak B, Sadowski R, Chlebowska J, Firczuk M, Bujnicki JM, Staruch AD, Zagozdzon R, et al. Statins impair glucose uptake in human cells. BMJ Open Diabetes Research and Care 20142 e000017. (https://doi.org/10.1136/ bmjdrc-2014-000017)

33 Smith R, Solberg R, Jacobsen LL, Voreland AL, Rustan AC, Thoresen GH \& Johansen HT. Simvastatin inhibits glucose metabolism and legumain activity in human myotubes. PLOS ONE 20149 e85721. (https://doi.org/10.1371/journal.pone.0085721)

34 Kuzyk CL, Anderson CC \& Roede JR. Simvastatin induces delayed apoptosis through disruption of glycolysis and mitochondrial impairment in neuroblastoma cells. Clinical and Translational Science 202013 563-572. (https://doi.org/10.1111/cts.12740)

35 Kwak HB, Thalacker-Mercer A, Anderson EJ, Lin CT, Kane DA, Lee NS, Cortright RN, Bamman MM \& Neufer PD. Simvastatin impairs ADP-stimulated respiration and increases mitochondrial oxidative stress in primary human skeletal myotubes. Free Radical Biology and Medicine 201252 198-207. (https://doi.org/10.1016/j. freeradbiomed.2011.10.449)

36 Sakamoto K \& Holman GD. Emerging role for AS160/TBC1D4 and TBC1D1 in the regulation of GLUT4 traffic. American Journal of Physiology-Endocrinology and Metabolism 2008295 E29-E37. (https:// doi.org/10.1152/ajpendo.90331.2008)

37 Treebak JT, Glund S, Deshmukh A, Klein DK, Long YC, Jensen TE, Jorgensen SB, Viollet B, Andersson L, Neumann D, et al. AMPKmediated AS160 phosphorylation in skeletal muscle is dependent on AMPK catalytic and regulatory subunits. Diabetes $2006 \mathbf{5 5}$ 2051-2058. (https://doi.org/10.2337/db06-0175)

38 Hilder TL, Baer LA, Fuller PM, Fuller CA, Grindeland RE, Wade CE \& Graves LM. Insulin-independent pathways mediating glucose uptake in hindlimb-suspended skeletal muscle. Journal of Applied Physiology 200599 2181-2188. (https://doi.org/10.1152/ japplphysiol.00743.2005)

39 Goode N, Hughes K, Woodgett JR \& Parker PJ. Differential regulation of glycogen synthase kinase- $3 \beta$ by protein kinase $\mathrm{C}$ isotypes. Journal of Biological Chemistry 1992267 16878-16882. 
40 Dekker LV \& Parker PJ. Protein kinase C - a question of specificity. Trends in Biochemical Sciences 199419 73-77. (https://doi. org/10.1016/0968-0004(94)90038-8)

41 Lilja JJ, Kivisto KT \& Neuvonen PJ. Grapefruit juice increases serum concentrations of atorvastatin and has no effect on pravastatin. Clinical Pharmacology and Therapeutics 199966 118-127. (https://doi. org/10.1053/cp.1999.v66.100453001)
42 Taha DA, De Moor CH, Barrett DA, Lee JB, Gandhi RD, Hoo CW \& Gershkovich P. The role of acid-base imbalance in statin-induced myotoxicity. Translational Research 2016174 140-160.e14. (https:// doi.org/10.1016/j.trsl.2016.03.015)

43 Varlamov O, Bethea CL \& Roberts CT, Jr. Sex-specific differences in lipid and glucose metabolism. Frontiers in Endocrinology 20145241. (https://doi.org/10.3389/fendo.2014.00241)

Received in final form 14 October 2020

Accepted 29 October 2020

Accepted Manuscript published online 29 October 2020
This work is licensed under a Creative Commons Attribution-NonCommercial-NoDerivatives 4.0 elfternationablicense $i$ ica.com at $04 / 26 / 2023$ 02:43:26AM 